\title{
Fate of Listeria innocua during production and ripening of smeared hard cheese made from raw milk
}

\author{
P. Hammer, ${ }^{*}$ W. Bockelmann, $\dagger$ and W. Hoffmann* ${ }^{* 1}$ \\ *Department of Safety and Quality of Milk and Fish Products, and \\ †Department of Microbiology and Biotechnology, Max Rubner-Institut, 24103 Kiel, Germany
}

\begin{abstract}
The fate of 2 different Listeria innocua strains was analyzed during the production and ripening of smeared raw milk Greyerzer cheese (Gruyère). These strains were used as surrogates for the pathogenic Listeria monocytogenes, as they are physiologically very similar. Bacterial cells were added to the cheese milk at levels of $10^{5} \mathrm{cfu} / \mathrm{mL}$. During the first $24 \mathrm{~h}$ of cheese making, the number of the test strains decreased to a level of below $10^{2} \mathrm{cfu} / \mathrm{g}$. Obviously, the cooking temperature of $56^{\circ} \mathrm{C}$ and the subsequent slight temperature decrease to $50^{\circ} \mathrm{C}$ within $70 \mathrm{~min}$ contributed to a distinct reduction of Listeria counts. The counts in the cheese cores did not exceed $10^{3} \mathrm{cfu} / \mathrm{g}$ within 12 wk of cheese ripening and Listeria was not detectable after 24 wk. In contrast to the cores of the cheeses of the 4 batches in this study, their rinds always contained a high listerial load of approximately $10^{6}$ to $10^{8} \mathrm{cfu} / \mathrm{g}$ throughout the entire ripening period. The smeared surface showed an increase of $\mathrm{pH}$ to alkaline values, corresponding to smear microbiota development. Coryneforms and Staphylococcus counts were stable at $>10^{7} \mathrm{cfu} / \mathrm{cm}^{2}$ over $175 \mathrm{~d}$, whereas yeast counts decreased to about $10^{5} \mathrm{cfu} / \mathrm{cm}^{2}$ at the end of ripening. The study shows that the smear culture had no noticeable anti-listerial potential. When removing the rind or portioning such smeared cheese loaves with a cutting device, a postprocess contamination of the core might occur, thus presenting a major hygienic risk.
\end{abstract}

Key words: Listeria innocua, raw milk cheese, cheese production, smear culture, anti-listerial potential

\section{INTRODUCTION}

Microbiological food safety criteria for Listeria monocytogenes in ready-to-eat (RTE) foods in Europe were stipulated in regulations (European Union) 2073/2005

Received March 2, 2017.

Accepted June 5, 2017.

${ }^{1}$ Corresponding author: wolfgang.hoffmann@mri.bund.de and 1441/2007 (Commission of the European Communities, 2005, 2007). Marketed RTE foods that do not support growth of L. monocytogenes have to comply with a limit of $100 \mathrm{cfu} / \mathrm{g}$ throughout their shelf life. The organism must be absent in $25 \mathrm{~g}$ of product at the end of production if the RTE foods are able to support the growth of L. monocytogenes.

The behavior of potentially pathogenic Listeria in hard and semi-hard cheese during manufacture and ripening has been analyzed in several studies. Ryser and Marth (1987) examined the ability of L. monocytogenes to survive the Cheddar cheese making process and persist during foil ripening. Three inoculated strains survived for as long as 254 to $434 \mathrm{~d}$ in the cheese. Kaufmann (1989) inoculated L. monocytogenes and found that the organism was not detectable in the cheese body and on the surface of the hard cheeses Emmental and Greyerzer from the beginning to the end of the ripening period. The results of Bachmann and Spahr (1995) confirmed that Swiss hard cheeses (Emmental type) made from raw milk were hygienically safe after 1 wk of fabrication. The semi-hard cheeses (Tilsit type) were free from inoculated pathogens and their toxic metabolites, except for L. monocytogenes, which survived the manufacturing and ripening process and was detectable up to $90 \mathrm{~d}$ of ripening. Kovincic et al. (1991) examined the ability of $L$. monocytogenes to survive the cheesemaking process of semi-soft Trappist cheese, where the organism persisted during 3 mo of ripening and storage. The counts after 3 mo were in the same range as in the inoculated milk. Northolt et al. (1988) made Gouda and Maasdam cheese from Listeria-contaminated milk. During manufacture, Listeria was concentrated in the curd by a factor of 10 . Over a ripening period of $6 \mathrm{wk}$, the number of Listeria remained approximately constant. Yousef and Marth (1990) found that the Italian hard cheese Parmesan was not a favorable medium for the survival of $L$. monocytogenes. The pathogen was not detected in cheese after 2 to 16 wk of ripening, depending on the strain and batch of cheese. The behavior of inoculated L. monocytogenes on the surface of fully ripened Greek Graviera hard cheese was assessed by 
Giannou et al. (2009). Listeria monocytogenes did not grow on cheese surfaces, regardless of packaging and storage conditions. However, long-term survival (30-90 d) of the pathogen was noted in all treatments. Overall, the lower the temperature, the higher the survival rate was. Chatelard-Chauvin et al. (2015) investigated the behavior of L. monocytogenes in French raw milk Cantal-type uncooked cheese throughout cheese manufacture and storage in different packages. The numbers of the pathogen only increased during the first $24 \mathrm{~h}$ of cheese making and decreased significantly in both body and rind during ripening from d 45 to 360 .

Cheeses that are covered with red smear may have a greater risk of containing Listeria because it is a suitable medium for growth of $L$. monocytogenes (Terplan et al., 1996). A study of Rudolf and Scherer (2001) determined the incidence of Listeria and L. monocytogenes in European red smear cheeses. Surprisingly, a higher incidence of L. monocytogenes was observed in cheeses from pasteurized milk than in cheeses manufactured from raw milk. It was strongly recommended that red smear cheeses be monitored carefully by cheesemaking companies. Detailed studies are limited up to now. Schvartzman et al. (2011) modeled the fate of $L$. monocytogenes during manufacture and ripening of a smeared laboratory cheese made with pasteurized or raw milk. The curd was not pressed before brining and ripening for $28 \mathrm{~d}$. The general results indicate that as the cheese is delivered to the market, the relative risk from cheeses made from pasteurized milk is distinctly less than those made from raw milk. The anti-listerial potential of food-borne yeasts in the red smear of Tilsit and acid-curd cheese was investigated by Goerges et al. (2011). On the Tilsit, but not on the acid-curd cheeses, a decrease of Listeria cell numbers by 1 to 2 log units was observed. An inhibitory activity of coryneform bacteria and staphylococci found in the complex surface microbial ripening consortia of red smear cheeses toward $L$. monocytogenes has been reported by Valdés-Stauber et al. (1991) and Carnio et al. (1999). In a study of Pinto et al. (2009), the nonpathogenic Listeria innocua was used as a surrogate organism for the pathogenic $L$. monocytogenes because it is physiologically very similar and both can be isolated from cheese produced from raw milk. Kheadr et al. (2002) used L. innocua ATCC 33090 instead of L. monocytogenes to study the effect of dynamic high pressure on the microbiological quality of Cheddar cheese. Pressurization of milk resulted in a 3 - to 4-log cycle reduction of $L$. innocua colony-forming units. After $3 \mathrm{mo}$ of ripening, the Cheddar made of pressurized milk contained 1 to $3 \times 10^{2} \mathrm{cfu} / \mathrm{g}$, whereas L. innocua was not detected in Cheddar made from pasteurized milk.
The aim of this study was to investigate the fate of 2 inoculated strains of $L$. innocua as surrogates for L. monocytogenes during production and ripening of smeared hard cheese made of raw milk. The manufacturing process followed the production of Swiss hard cheese Greyerzer (Gruyère) and the whey/curd mixture was scalded at $56^{\circ} \mathrm{C}$. The ripening of the cheeses in this study was performed at high air humidity and at frequent applications of defined smear to analyze the survival of $L$. innocua on the cheese surface and in the interior.

\section{MATERIALS AND METHODS}

\section{Microbial Analysis of Cheese Microbiota}

Ten grams of cheese core samples were homogenized in a Stomacher blender (Miix 1, Kleinfeld Labortechnik, Gehrden, Germany) for 2 min at maximum speed in $90 \mathrm{~mL}$ of a pre-warmed $\left(45^{\circ} \mathrm{C}\right)$ aqueous solution of $2 \%$ sodium citrate. For analyses of surface microbiota, a rectangular 1- to 2-mm-thick slice from the cheese rind was cut off ( $10 \mathrm{~g}$ of cheese rind) and the size of the surface area was determined. This sample was homogenized as described above and 10-fold dilutions of quarter strength Ringer's solution were plated in duplicate on appropriate selective media. Two dilution steps (10-300 colonies) were used for colony counting. Cell counts were either expressed per centimeter ${ }^{2}$ or per gram of cheese (lactic acid bacteria in the cheese core). If not stated otherwise, growth media were purchased from VWR International (Darmstadt, Germany). Mesophilic and thermophilic lactic acid bacteria were plated on M17 agar $\left(25^{\circ} \mathrm{C}, 45^{\circ} \mathrm{C}, 2\right.$ to $\left.3 \mathrm{~d}\right)$ and on de Man, Rogosa, Sharpe agar (MRS; $30^{\circ} \mathrm{C}, 45^{\circ} \mathrm{C}, 2$ to 3 d), and the latter was incubated anaerobically. Aerobic surface smear microbiota were analyzed on modified milk agar (mMA $, 25^{\circ} \mathrm{C}, 5$ to $9 \mathrm{~d}$; Bockelmann et al., 2005), which is based on plate count agar enriched with milk, nitrogen, and vitamins resembling a mature smear cheese surface. Yeasts and molds were analyzed on yeast extract, glucose, chloramphenicol agar (YGC; $25^{\circ} \mathrm{C}, 3 \mathrm{~d}$ ), enterobacteria on violet red bile dextrose agar (VRBD, $30^{\circ} \mathrm{C}, 24 \mathrm{~h}$ ), enterococci on kanamycin, esculin, azide agar (KEA, $30^{\circ} \mathrm{C}, 2 \mathrm{~d}$ ), and pseudomonads on cetrimid fucidin cephalotin dextrose agar (CFCD $\left., 25^{\circ} \mathrm{C}, 2 \mathrm{~d}\right)$.

\section{Listeria Strains and Inoculum Preparation}

For inoculation of cheese milk, 2 strains of $L$. innосиа (90, serovar 6a; 114, serovar 6b) were chosen. Both were isolated in our Department of Microbiology 
Table 1. Samples, time of sampling, and test applied for the enumeration or detection of Listeria innocua during cheese-making

\begin{tabular}{llll}
\hline Sample & Time & Colony count $^{*}$ & Enrichment $^{1}$ \\
\hline Centrifuge sludge $^{2}$ & 0 & & $\mathrm{x}$ \\
Cheese milk not inoculated $_{\text {Cheese milk inoculated }}$ & 0 & $\mathrm{x}$ & $\mathrm{x}$ \\
Whey before cooking & $10 \mathrm{~min}$ & $\mathrm{x}$ & \\
Curd before cooking & $1.5 \mathrm{~h}$ & $\mathrm{x}$ & \\
Whey after cooking & $1.5 \mathrm{~h}$ & $\mathrm{x}$ & \\
Curd after cooking & $2.4 \mathrm{~h}$ & $\mathrm{x}$ & \\
Cheese before brining & $2.4 \mathrm{~h}$ & $\mathrm{x}$ & \\
Cheese after brining & $7 \mathrm{~h}$ & $\mathrm{x}$ & $\mathrm{x}$ \\
Cheese rind & $27 \mathrm{~h}$ & $\mathrm{x}$ & $\mathrm{x}$ \\
Cheese interior & $\mathrm{wk} 3,6,12,24$ & $\mathrm{x}$ & \\
\hline
\end{tabular}

${ }^{1}$ For enrichment, samples of $25 \mathrm{~g}$ were used (for wk 24, only $10 \mathrm{~g}$ was available); for cheese samples, only applied if no count was obtained.

${ }^{2}$ For fat standardization and cleaning, the cheese milk was centrifuged and the sludge was tested in addition to the raw milk to prove that Listeria was not present in the cheese milk.

and Biotechnology from different German smeared soft cheeses. Final identification and serotyping of the strains were performed at the Listeria reference laboratory at the University of Wuerzburg, Germany. Culture strains were streaked onto sheep blood agar [Columbia agar base supplemented with $5 \%$ ( vol/vol) defibrinated sheep blood, both from Oxoid, Wesel, Germany] directly from $-80^{\circ} \mathrm{C}$ stock and incubated for $24 \mathrm{~h}$ at $37^{\circ} \mathrm{C}$. One colony from each strain was inoculated into $10 \mathrm{~mL}$ of trypticase soy broth (Oxoid) and incubated as above. Subsequently, $500 \mathrm{~mL}$ of trypticase soy broth was inoculated with $1 \mathrm{~mL}$ of the culture and incubated for $24 \mathrm{~h}$ at $37^{\circ} \mathrm{C}$ on a shaker $(100 \mathrm{rpm})$. Of this broth $10 \mathrm{~mL}$ was centrifuged for $10 \mathrm{~min}$ at $5,000 \times g$ at room temperature to harvest the Listeria. The pellet was resuspended in $100 \mathrm{~mL}$ of whole UHT milk $(3.5 \%$ fat). Before adding the inoculum of single strains to the cheese milk, it was stored at room temperature for 30 min for milk adaptation of the strains. To determine the colony count of the inoculum, $1 \mathrm{~mL}$ was removed and diluted to $10^{-8}$ in $0.85 \%$ (wt/vol) $\mathrm{NaCl}$ (Merck, Darmstadt, Germany) supplemented with $0.1 \%$ (wt/ vol) tryptone (Oxoid; NaCl-tryptone). Two plates of blood agar were inoculated in spread technique with 0.1 $\mathrm{mL}$ each from each dilution step. Colony counts were approximately $10^{8} \mathrm{cfu} / \mathrm{mL}$, which resulted in colony counts of the cheese milk of approximately $10^{5} \mathrm{cfu} / \mathrm{mL}$ (100 mL of inoculum mixed with $100 \mathrm{~kg}$ of raw milk).

\section{Detection of Listeria During Cheese-Making}

For sampling times and the detection methods applied regarding the tested samples, see Table 1. To determine colony counts of $L$. innocua during cheesemaking in fluid samples (milk, whey), the method as described above was applied; however, instead of blood agar PALCAM agar (Oxoid) was used. Solid samples (curd, cheese, centrifuge sludge) were homogenized 1:10 (wt/vol) either in NaCl-tryptone for colony count (see above) or in 1/2 strength Fraser broth (Merck) for enrichment. Detection of the Listeria strains via enrichment was performed according to ISO (2005), with the modification that only one solid medium (polymyxinacriflavine-LiCl-ceftazidime-mannitol-agar) was used for detection. For separate investigation of cheese rind and interior, a slice of approximately $5 \mathrm{~cm}$ thickness was cut off the cheese loaf. Using sterile spatulas, approximately $5 \mathrm{~mm}$ of the rind was removed from the entire piece and used as a sample. The surface of the remaining part was scraped with a long, sterile knife with one move. This procedure was repeated once, and material of the cheese interior was obtained with sterile spoons from the center of the prepared surface.

\section{Chemical and Physical Analysis of Cheese}

To monitor the cheese production process, acidification of each batch was analyzed during manufacture and ripening using a $\mathrm{pH}$ meter. The contents of DM, fat, protein, and $\mathrm{NaCl}$ in cheese after 12 and 24 wk of ripening were determined according to German standard methods (VDLUFA, 2003). Each parameter was analyzed in triplicate. For analysis, one-half of a cheese loaf (bread form) was de-rinded $(1 \mathrm{~cm})$ and divided into 3 pieces of the same size with a thickness of about $4 \mathrm{~cm}$. The pieces had an increasing distance to the one end of the "bread" and were marked as PA, PB, and PC.

\section{Cheese Production}

Raw cow milk from the experimental farm of the Max Rubner-Institut (Kiel, Germany) was used for cheese production. The production facilities are regularly used for production of cheese as food, so for safety reasons 
Table 2. Process sheet and sampling during the production of Greyerzer cheese

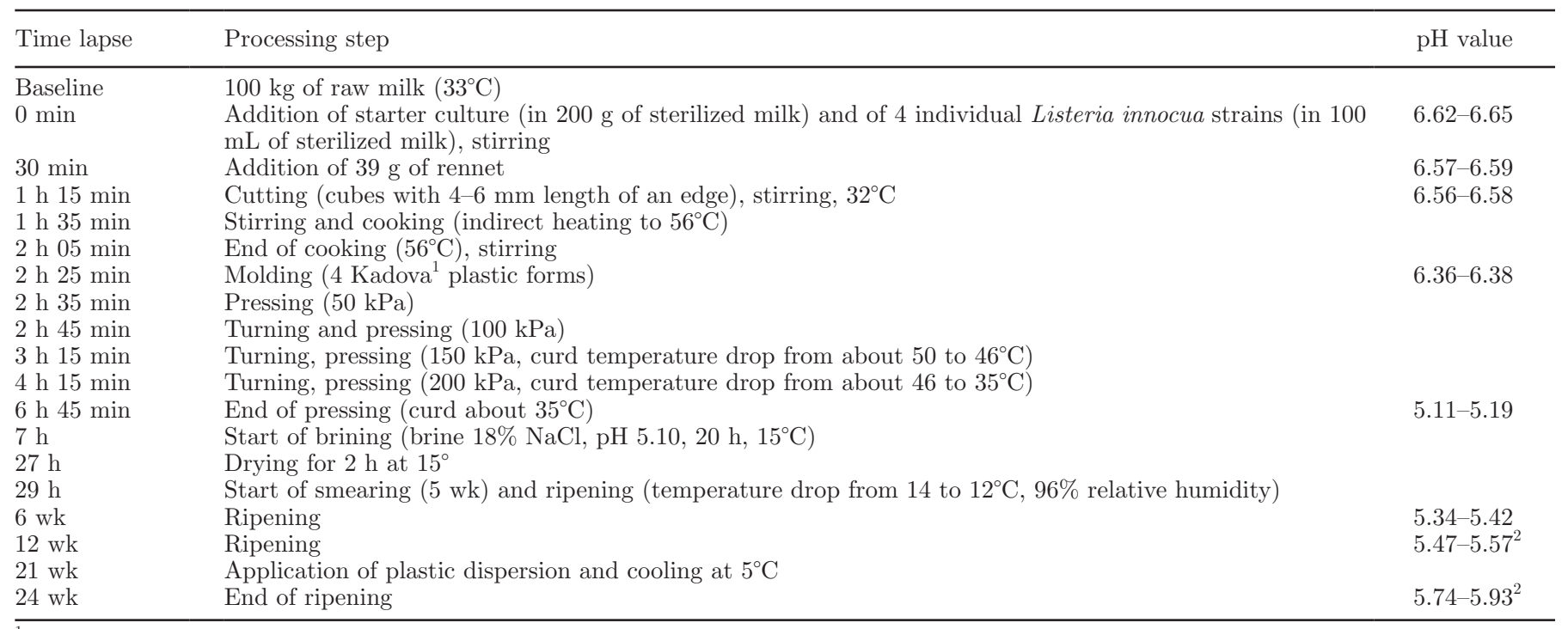

${ }^{1}$ Kadova plastic forms (Be-St Holland-Products, Bergen op Zoom, the Netherlands.

${ }^{2}$ Core of the cheeses (de-rinded piece PC).

L. innocua was used as a surrogate. Three batches of raw milk were processed (each of these tested for the presence of Listeria; Table 1). One batch was used for 2 cheese vats that were not inoculated with Listeria. The other 2 batches were used for 4 cheese vats that were inoculated either with $L$. innocua 90 or with $L$. innocua 114. Each strain was added to milk of the 2 different batches (A, B). Each batch was processed independently in 2 cheese vats of $50 \mathrm{~kg}$.

The processing steps of cheese manufacture are summarized in Table 2. One hundred kilograms of raw milk was warmed to $33^{\circ} \mathrm{C}$ in a cheese vat. Two hundred grams of starter culture (FD-DVS RSF-736; Chr. Hansen, Nienburg, Germany; 10 units dispersed for $30 \mathrm{~min}$ in $200 \mathrm{~g}$ of sterile milk at $30^{\circ} \mathrm{C}$ ) and $100 \mathrm{~g}$ of Listeria culture was added under agitation, resulting in about $10^{5} \mathrm{cfu} / \mathrm{mL}$ of Listeria in the cheese milk. After ripening of the milk for $30 \mathrm{~min}, 40 \mathrm{~g}$ of rennet (Naturen Premium 145, Chr. Hansen) diluted in $200 \mathrm{~g}$ of water was added. The coagulum was cut into 4- to $6-\mathrm{mm}$ cubes after $45 \mathrm{~min}$. Following agitation for $20 \mathrm{~min}$, the mixture of curd and whey was heated indirectly to $56^{\circ} \mathrm{C}$ within $30 \mathrm{~min}$. This temperature was held for 20 min under continuous agitation before the pre-pressed curd was transferred into 4 Kadova plastic cheese molds $(24.5 \times 11.4 \times 13.3 \mathrm{~cm}$; Be-St Holland-Products, Bergen op Zoom, the Netherlands). They consisted of the mold with a suitable lining inside, a lid, and a lid lining. The curd was treated with increasing pressure: first $10 \mathrm{~min}$ at $50 \mathrm{kPa}$, then $30 \mathrm{~min}$ at $100 \mathrm{kPa}, 60$ min at $150 \mathrm{kPa}$, and $150 \mathrm{~min}$ at $200 \mathrm{kPa}$. The curd loaves were turned between the 4 pressing cycles. Dur- ing pressing, the temperature of the loaves decreased to about $34^{\circ} \mathrm{C}$. The forms were removed after $17 \mathrm{~h}$, brined $[18 \%$ (wt/wt) sodium chloride, $\mathrm{pH} 5.1$ adjusted with lactic acid] for $16 \mathrm{~h}$ at $15^{\circ} \mathrm{C}$, and dried for $2 \mathrm{~h}$ at $15^{\circ} \mathrm{C}$. Subsequently, cheeses were ripened for $24 \mathrm{wk}$ at 14 to $12^{\circ} \mathrm{C}$ and a relative humidity ( $\left.\mathbf{r h}\right)$ of $96 \%$. During the first $3 \mathrm{wk}$ of ripening, the loaves were smeared 3 times a week. In the following $2 \mathrm{wk}$, smearing was applied 4 times. Further surface treatment was limited to an application of a salt solution [5\% (wt/wt) sodium chloride] without smear if the surfaces looked too dry. For the last 3 wk of ripening, the cheese surface was coated twice with a plastic dispersion (IP Ingredients, Suederluegum, Germany). This dispersion consisted of fluid plastic, was applied with a brush, and hardened to a flexible coating, which was permeable for gas and humidity.

The manufacturing conditions of the experimental hard cheese were based on recommendations of $\mathrm{W}$. Bisig (Forschungsanstalt Agroscope Liebefeld-Posieux, Bern, Switzerland, personal communication). The homofermentative starter culture contained Lactococcus lactis ssp. cremoris, Lc. lactis ssp. lactis, Lactobacillus helveticus, and Streptococcus thermophilus. The smear culture contained $10^{7} \mathrm{cfu} / \mathrm{mL}$ of Staphylococcus equorum 91031, Corynebacterium casei 95149, Brevibacterium linens 95160, and Microbacterium gubbeenense 95152, respectively. This smear culture also contained 2 yeasts: $10^{6} \mathrm{cfu} / \mathrm{mL}$ of Debaryomyces hansenii 6004 and Geotrichum candidum 6215, respectively. They were dispersed in sterilized potable water with $5 \%$ (wt/wt) sodium chloride. All strains of the smear culture were from the 
strain collection of the Department for Microbiology and Biotechnology in Kiel and were originally isolated from smear cheeses.

\section{RESULTS}

\section{Chemical and Physical Analysis of Ripened Cheese}

Chemical and physical results at 12 wk and at end of ripening are presented in Table 3. At the end of ripening, the fat content in DM was about $50 \%$ in all samples and the protein content was about $28 \%$. Dry matter of all pieces was between 61.4 and $64.2 \%$ after $12 \mathrm{wk}$ and between 63.3 and $67.3 \%$ after $24 \mathrm{wk}$ of ripening. The $\mathrm{DM}$ and the content of $\mathrm{NaCl}$ decreased from the outer de-rinded pieces (PC) to the inner de-rinded pieces (PA). The content of $\mathrm{NaCl}$ was between 1.4 and $1.9 \%$ after $12 \mathrm{wk}$ and between 1.5 and $2.0 \%$ after $24 \mathrm{wk}$. The slight increase was a result of the time-dependent increase of DM. The ripening process can be illustrated with the course of the $\mathrm{pH}$ values.

\section{Cheese Microbiota}

The microbiota of the cheese core was typical for raw milk cheeses. Starter lactic acid bacteria showed typically high counts $\left(10^{9} \mathrm{cfu} / \mathrm{g}\right)$ after 1 wk of ripening and decreased to $10^{6} \mathrm{cfu} / \mathrm{g}$ over the ripening period of $175 \mathrm{~d}$ (Figure 1). The counts of (non-)starter lactic acid bacteria increased within $40 \mathrm{~d}$ of ripening and were stable at about $10^{8} \mathrm{cfu} / \mathrm{g}$ throughout the entire ripening period. Enterococcus counts ranged between $10^{4}$ to $10^{5} \mathrm{cfu} / \mathrm{g}$, with no substantial deviation during the ripening period; enterobacteria were below the detection limit of $100 \mathrm{cfu} / \mathrm{g}$ throughout the ripening period.

The surface showed an increase of $\mathrm{pH}$ to alkaline values corresponding to the smear microbiota development (Figure 2). The initially high yeast counts (YGC, $\left.>10^{7} \mathrm{cfu} / \mathrm{cm}^{2}\right)$ decreased during ripening to $<10^{5} \mathrm{cfu} / \mathrm{g}$. Highest bacterial counts $\left(>10^{9} \mathrm{cfu} / \mathrm{cm}^{2}\right)$ were observed for coryneforms and other rods on mMA. Staphylococcus counts (mMA) were stable at $>10^{8} \mathrm{cfu} / \mathrm{cm}^{2}$ over 175 d. Enterococcus counts (KEA) were between $10^{7}$ to $10^{8} \mathrm{cfu} / \mathrm{cm}^{2}$ over $175 \mathrm{~d}$; enterobacterial counts dropped from $10^{5}$ to $<10^{3} \mathrm{cfu} / \mathrm{cm}^{2}$ (Figure 2). Pseudomonads were only detected on CFCD agar at 2 sampling points in 3 cheese batches (approximately $10^{3} \mathrm{cfu} / \mathrm{cm}^{2}$, Figure 2).

\section{Survival of Listeria}

To achieve measurable results, Listeria was added to the cheese milk at relatively high levels of $10^{5} \mathrm{cfu} / \mathrm{mL}$. Samples of cheese milk and centrifuge sludge $(25 \mathrm{~mL}$ or
$25 \mathrm{~g}$, respectively) from the skimming centrifuge were drawn in advance of inoculation and were tested for the presence of Listeria. None of these samples yielded a positive result.

During the first $27 \mathrm{~h}$ of cheese-making (until the end of brining), the number of both test strains decreased in the curd to a level $<10^{2} \mathrm{cfu} / \mathrm{g}$ (Table 4 ). Only the first samples were taken in milk after inoculation whereas subsequent analysis was performed in curd/cheese. The whey in our study was removed after $2.4 \mathrm{~h}$ and showed colony counts between $3.3 \times 10^{2}$ and $1.8 \times 10^{3} \mathrm{cfu} / \mathrm{mL}$. Obviously, the high cooking temperature of $56^{\circ} \mathrm{C}$ and the subsequent temperature decrease to $50^{\circ} \mathrm{C}$ within 70 min (see Table 2) contributed to a distinct reduction of Listeria counts. This temperature is selective for the microbial flora and inhibits growth of undesired microorganisms. It was applied to determine the survival rate of the 2 inoculated Listeria strains. In Figure 3A and $3 \mathrm{~B}$ the colony counts for both strains are plotted starting with cheese before brining $(7 \mathrm{~h})$ and during the entire ripening period. After the development of the cheese rind (wk 3), counts for rind and core were performed separately. The bacterial count of the core was below $10^{3} \mathrm{cfu} / \mathrm{g}$ after 6 and 12 wk of ripening, and Listeria was no longer detectable after 24 wk. Interestingly, colony counts of both Listeria strains in the core increased during the first $20 \mathrm{~d}$ of ripening.

\section{DISCUSSION}

Kaufmann (1989) inoculated L. monocytogenes at a comparable level into raw cheese milk for Greyerzer. The cooking temperature was even higher at $57^{\circ} \mathrm{C}$. The high thermal input and a decrease to $50^{\circ} \mathrm{C}$ within $6 \mathrm{~h}$ prevented growth of L. monocytogenes, with the result that the organism was not detectable until the end of ripening. Bachmann and Spahr (1995) achieved comparable results in Swiss hard cheeses made from raw milk. Inoculated milk for semi-hard Gouda or Maasdam cheese contained only $5 \times 10^{2} \mathrm{cfu} / \mathrm{mL}$ of $L$. monocytogenes (Northolt et al., 1988). In this study, Listeria counts increased to about $2 \times 10^{4} \mathrm{cfu} / \mathrm{mL}$ during cheese manufacture (maximum temperature $35.5^{\circ} \mathrm{C}$ ) and decreased during ripening at 88 or $92 \%$ rh at $13^{\circ} \mathrm{C}$ to $>10^{3} \mathrm{cfu} / \mathrm{g}$ in the interior and to $1.3 \times 10^{3}$ on the surface. The decimal reduction times (D values) for the most heat-resistant strain of L. monocytogenes were 17 $\mathrm{s}$ at $64^{\circ} \mathrm{C}$ and $8 \mathrm{~s}$ at $66^{\circ} \mathrm{C}$. Yousef and Marth (1990) inoculated raw milk for Parmesan cheese with 2 strains of L. monocytogenes at a final concentration of $10^{4}$ to $10^{5}$ cells $/ \mathrm{mL}$. Curd was cooked at $51^{\circ} \mathrm{C}$ for $45 \mathrm{~min}$, and Listeria counts decreased only slightly. During cheese ripening at $13^{\circ} \mathrm{C}$ and $70 \% \mathrm{rh}$, Listeria was not detected after 2 to 16 wk of ripening, depending on the Listeria 
FATE OF LISTERIA INNOCUA IN SMEARED RAW MILK CHEESE

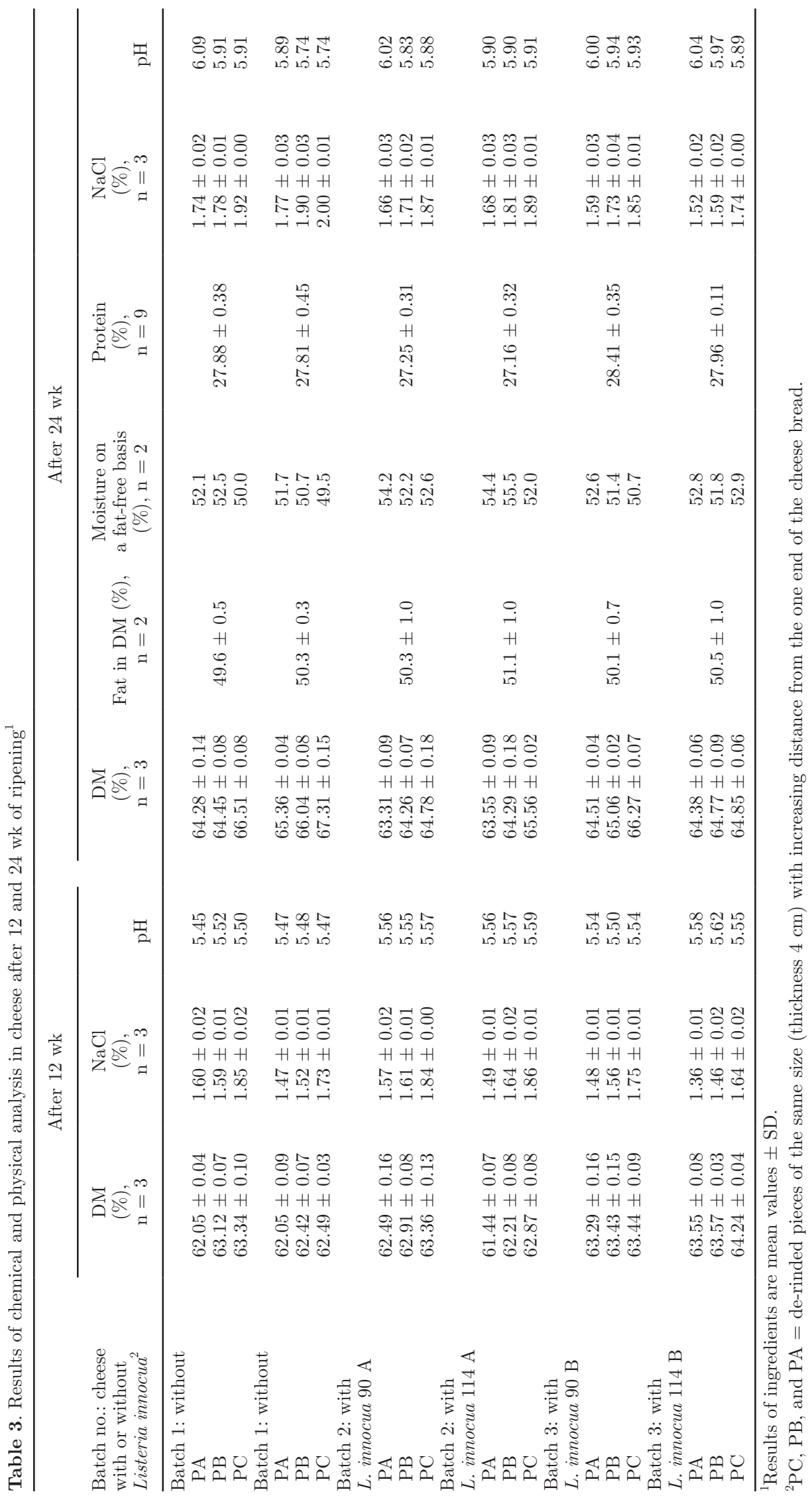


strain and the batch of cheese. During production of Grana Padano cheese, Ercolini et al. (2005) modeled the efficacy of scalding. Keeping the curd for $1 \mathrm{~h}$ at $55^{\circ} \mathrm{C}$ did not result in a reduction of $L$. monocytogenes (initial count approximately $10^{4} \mathrm{cfu} / \mathrm{mL}$ ). However, the data indicated that a first thermal stress induced by the cooking temperature was able by itself to affect the subsequent viability of Listeria and other pathogens. After further keeping of the curd at $55^{\circ} \mathrm{C}$, Listeria remained undetectable after the first hour level. In contrast, subsequent keeping at 45 or $38^{\circ} \mathrm{C}$ for $15 \mathrm{~min}$ simulating the faster cooling of the developing rind did not lead to a decrease. The cooking temperature in our experiments was $56^{\circ} \mathrm{C}$ and the decrease in temperature after draining during the next $5.5 \mathrm{~h}$ was about $4.5^{\circ} \mathrm{C}$ per hour in the curd interior (Table 2). Before brining, the curd interior was cooled to $35^{\circ} \mathrm{C}$ at a room temperature of about $26^{\circ} \mathrm{C}$. At this time the level of $L$. innocua was below or near the detection limit. Obviously, this course of temperature was also sufficient to inactivate the Listeria in the core of our small loaves. Comparing the survival of Listeria in our study and in other cited experiments, it must be considered that 2 different species were used. It was already mentioned that Kheadr et al. (2002) and Pinto et al. (2009) used $L$. innocua as a surrogate for L. monocytogenes because it is physiologically very similar and both can be isolated from cheese produced from raw milk. Boyer et al. (2009) compared the survival of both species in chill brines $(7.9$ and $13.2 \% \mathrm{NaCl})$ containing lactic acid bacteria. The cell membrane function of $L$. innocua is more electronegative and variable in its Lewis acid-base characteristics as a function of temperature. Membrane function is essential in the mechanism for surviving environmental stressors, such as salt, $\mathrm{pH}$, and water activity (Russell et al., 1995). The results of Boyer et al. (2009) showed that $L$. innocua was less resilient than L. monocytogenes after some days in the brine. The behavior against thermal input was not analyzed.

Giannou et al. (2009) used pieces of fully ripened Greek hard Graviera cheese that were inoculated with a 5 -strain cocktail of $L$. monocytogenes at approximately $3 \log \mathrm{cfu} / \mathrm{cm}^{2}$ on the surface. These experiments simulated a postprocess contamination during retail operations. Listeria did not grow on the surface up to $90 \mathrm{~d}$, regardless of packaging conditions and different storage

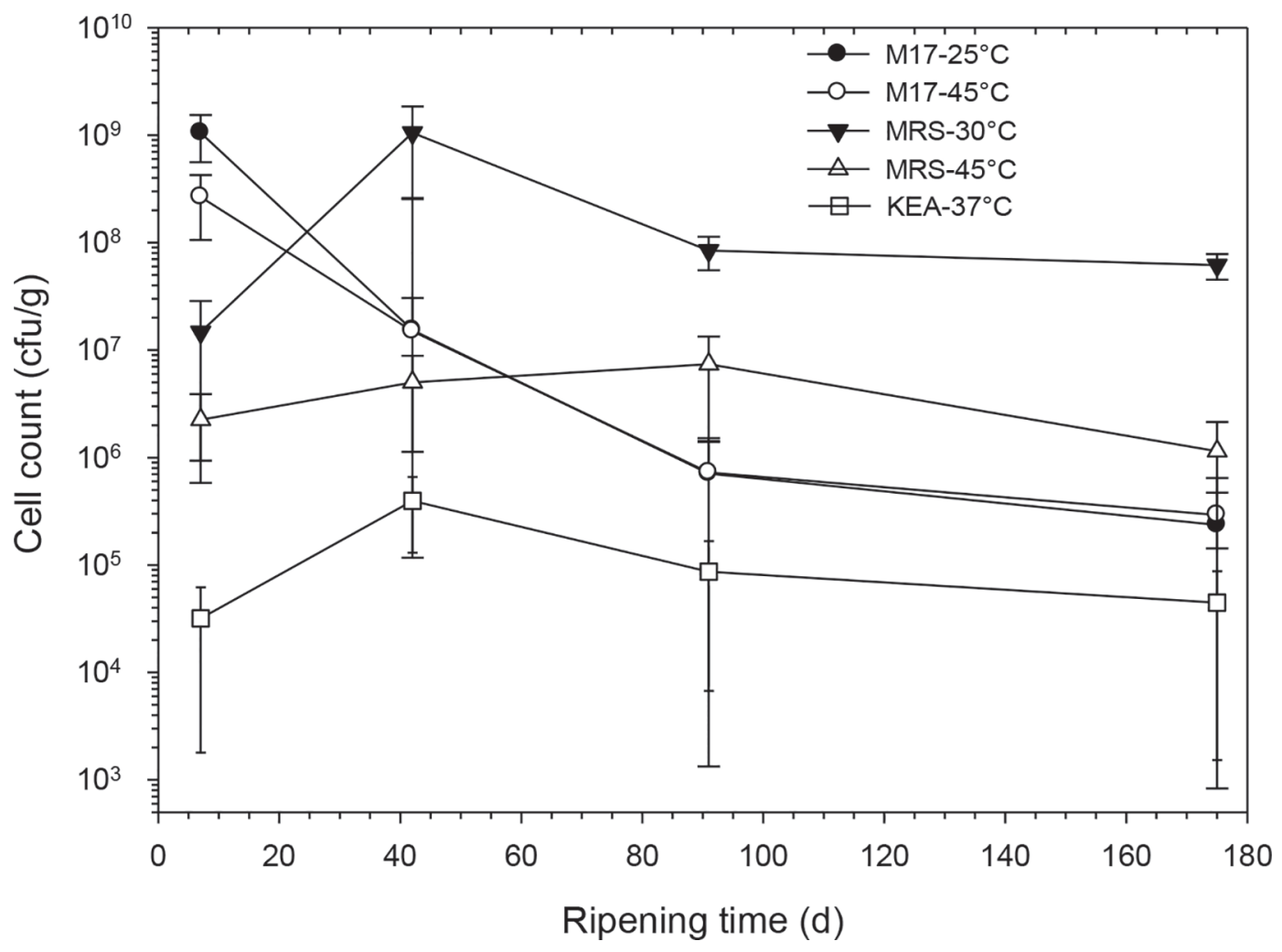

Figure 1. Bacterial growth in the cheese core of 6 different cheese batches produced from raw milk. Mesophilic and thermophilic cocci were plated onto M17 agar; mesophilic and thermophilic lactobacilli onto de Man, Rogosa, and Sharpe agar (MRS); and enterococci onto kanamycin, esculin, azide agar (KEA). The counts of enterobacteria (violet red bile dextrose agar; VRBD) were below the detection limit of $100 \mathrm{cfu} / \mathrm{g}$. Results are mean values and SD of batches. 


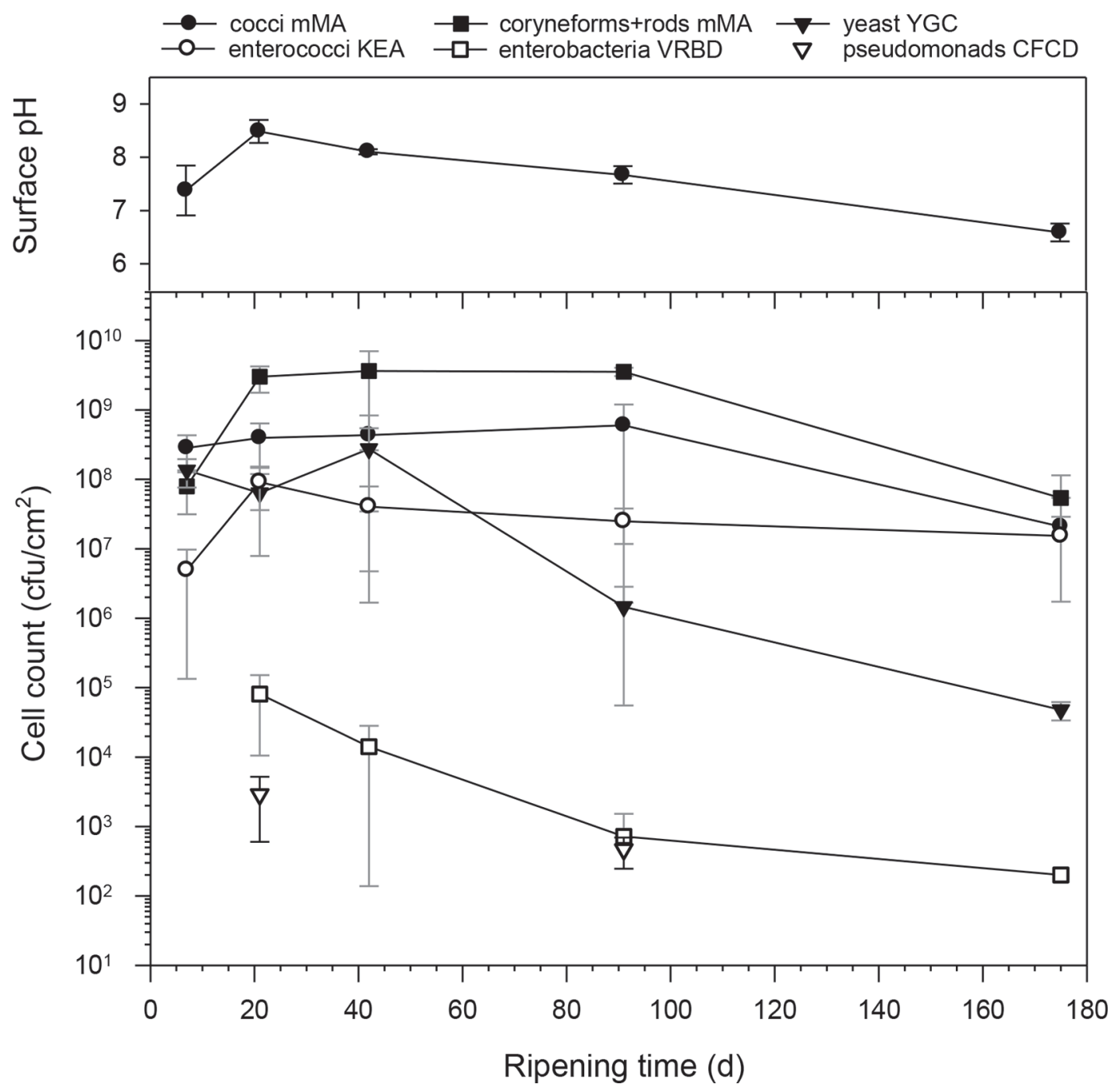

Figure 2. Development of the cheese smear: modified milk agar (mMA) was used for enumeration of cocci, coryneforms, and rods; yeast extract, glucose, chloramphenicol agar (YGC) for yeasts; violet red bile dextrose agar (VRBD) for enterobacteria; and kanamycin, esculin, azide agar (KEA) for enterococci. Pseudomonads plated on cetrimid fucidin cephalotin dextrose agar (CFCD) were detected at 2 sampling points only. Results are mean values and SD of the 6 experimental cheese batches.

Table 4. Colony counts of Listeria innocua strains 90 and 114 per $\mathrm{mL}$ or g during cheese-making and in the cheese interior (A, B: results from independent experiments)

\begin{tabular}{lcccc}
\hline Sample & $90 \mathrm{~A}$ & $90 \mathrm{~B}$ & $114 \mathrm{~A}$ & $114 \mathrm{~B}$ \\
\hline Cheese milk & $1.8 \times 10^{5}$ & $1.3 \times 10^{5}$ & $1.9 \times 10^{5}$ & $1.3 \times 10^{5}$ \\
Curd before cooking & $1.3 \times 10^{4}$ & $5.4 \times 10^{5}$ & $3.3 \times 10^{5}$ & $6.3 \times 10^{5}$ \\
Curd after cooking & $4.5 \times 10^{2}$ & $2.8 \times 10^{3}$ & $4.7 \times 10^{2}$ & $3.1 \times 10^{3}$ \\
Cheese before brining & $2.0 \times 10^{1}$ & $3.0 \times 10^{1}$ & $4.3 \times 10^{1}$ & $2.0 \times 10^{1}$ \\
Cheese after brining & $<10^{*}$ & $<10^{*}$ & $2.0 \times 10^{1}$ & $<10^{*}$ \\
Cheese wk 1 & $<10^{*}$ & $<10^{*}$ & $1.8 \times 10^{2}$ & $<10^{*}$ \\
Cheese wk 3 & $1.7 \times 10^{2}$ & $4.0 \times 10^{3}$ & $4.2 \times 10^{2}$ & $3.4 \times 10^{3}$ \\
Cheese wk 6 & $1.0 \times 10^{1}$ & $5.0 \times 10^{1}$ & $2.1 \times 10^{2}$ & $1.1 \times 10^{2}$ \\
Cheese wk 12 & $3.0 \times 10^{2}$ & $1.0 \times 10^{1}$ & $1.1 \times 10^{2}$ & $1.3 \times 10^{2}$ \\
Cheese wk 24 & $<10 \dagger$ & $<10 \dagger$ & $<10 \ddagger$ & $<10 \dagger$ \\
\hline
\end{tabular}

*Enrichment of $25 \mathrm{~g}$ positive.

$\dagger$ Enrichment of $10 \mathrm{~g}$ positive.

$\ddagger$ Enrichment of $10 \mathrm{~g}$ negative. 

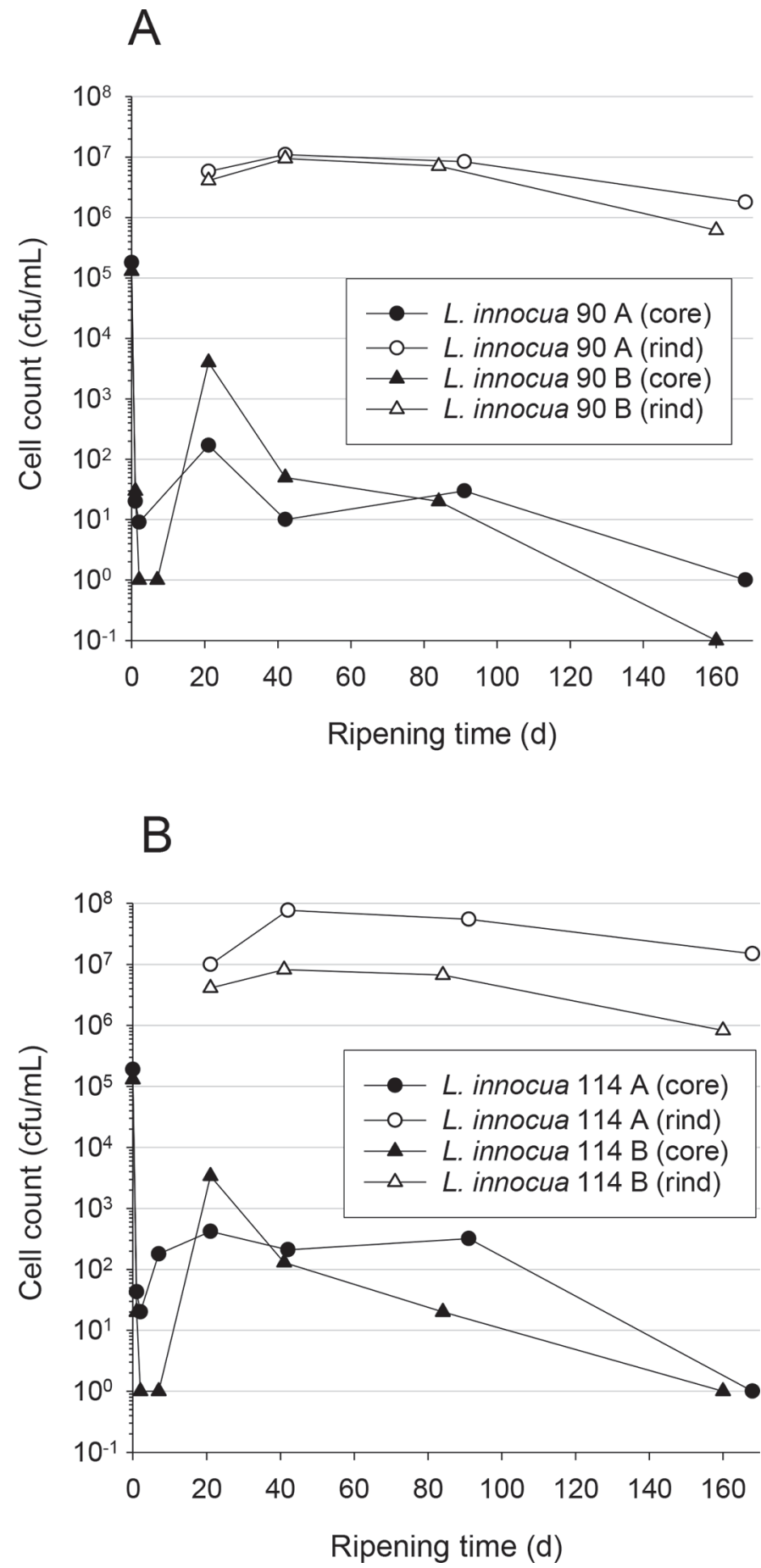

Figure 3. Colony counts of Listeria innocua after inoculation in cheese milk and on the rind and in the interior of cheese during ripening (starts with cheese before brining): (A) strain 90, and (B) strain 114 (A and B were independent experiments). For graphical reasons, values for $24 \mathrm{wk}$ were set at 1.0 if enrichment of $10 \mathrm{~g}$ was positive and at 0.1 if enrichment was negative. temperatures. Interestingly, colony counts of both Listeria strains in the core increased during the first 20 d of ripening. Ryser and Marth (1987) previously reported that the initial Listeria count in cheese milk for Cheddar after inoculation of 3 different strains was 2 to $3 \times 10^{2} / \mathrm{mL}$ and remained almost constant in the Cheddar curd (cooking temperature $39^{\circ} \mathrm{C}$ ) until pressing. All 3 Listeria strains survived for as long as 251 to $434 \mathrm{~d}$ at 6 and $13^{\circ} \mathrm{C}$ in the experimental Cheddar. During the first 14 to $28 \mathrm{~d}$, counts of all strains increased 0.1 to $0.8 \log \mathrm{cfu} / \mathrm{g}$ in cheese at the 2 ripening temperatures. These surprising data are in contrast to the results of Kaufmann (1989) and Bachmann and Spahr (1995), but confirm our results during the first $20 \mathrm{~d}$ of ripening (Table 4). Ryser and Marth (1987) did not discuss possible reasons for the occurrence of these peaks. One reason could be that the hygienic "hurdles" present in the core (salt, $\mathrm{pH}$, water activity value, competitive flora) took a long time to work effectively. In addition, the relatively small loaves in our study resulted in a faster decline of core temperature than in the original size Greyerzer loaves. However, the rind temperature was only affected a little by the loaf size.

Chatelard-Chauvin et al. (2015) prepared a cocktail of 5 strains of L. monocytogenes. This cocktail was inoculated in raw cheese milk for the manufacture of French Cantal type uncooked semi-hard cheeses. However, the milk contained only $6 \mathrm{cfu} / \mathrm{mL}$ of Listeria after inoculation. The cheeses were ripened at $9^{\circ} \mathrm{C}$ and $96 \% \mathrm{rh}$ for $360 \mathrm{~d}$. After various stages in the ripening process, portions of the cheeses were stored in different packages and storage temperatures for up to $45 \mathrm{~d}$. Counts of L. monocytogenes only increased during the first $24 \mathrm{~h}$ of cheese making to $10^{3}$ to $10^{4} \mathrm{cfu} / \mathrm{mL}$ and decreased significantly in both cores and rinds during ripening at $9^{\circ} \mathrm{C}$ from d 45 to $\mathrm{d} 360$. The decrease continued in the cores during storage in all 3 package types. In the rind, counts of L. monocytogenes decreased most significantly in nonpermeable kraft paper (cheese wrapped in kraft paper + plastic stretch film covering core) at low water activity $(<0.90)$ compared with plastic packs. Kovincic et al. (1991) inoculated pasteurized cheese milk for manufacture of semi-soft Trappist cheese and found initial counts between $2.9 \times 10^{2}$ and $2.4 \times 10^{5} \mathrm{cfu} /$ $\mathrm{mL}$. The curd was scalded at $39^{\circ} \mathrm{C}$ for $45 \mathrm{~min}$. After ripening and storage of the waxed cheeses at $10^{\circ} \mathrm{C}$ for $90 \mathrm{~d}$, Listeria counts ranged from $4.4 \times 10^{2}$ to $4.4 \times$ $10^{5} \mathrm{cfu} / \mathrm{g}$.

In contrast to the cores of the 4 cheese batches in our study, the smeared rind always contained a high listerial load of approximately $10^{7}$ and up to $10^{8} \mathrm{cfu} / \mathrm{g}$ for up to half of the ripening period (Figure 3). Listeria counts decreased slightly at the end of ripening to $10^{6}$ 
$\mathrm{cfu} / \mathrm{g}$. This might be a result of the applied plastic dispersion $3 \mathrm{wk}$ before the end of ripening.

Schvartzman et al. (2011) studied brined cheese curds after laboratory-scale production that were manually smeared one time and subsequently ripened at $13^{\circ} \mathrm{C}$ and $90 \%$ rh for $2 \mathrm{wk}$, followed by another 2 wk at $8^{\circ} \mathrm{C}$. The raw or pasteurized cheese milk used was inoculated with a single strain of $L$ monocytogenes at a final concentration of about $5 \times 10^{2} \mathrm{cfu} / \mathrm{mL}$. Results indicated that in cheeses made from pasteurized milk, less Listeria (almost $2 \mathrm{log}$ ) survived than in cheeses made from raw milk. During the short ripening period of $28 \mathrm{~d}$, the listerial load in the core and on the rind was at the same level after smearing. Goerges et al. (2011) investigated the anti-listerial potential of foodborne yeasts in red smear cheese. Their screening list of 175 strains also contained 2 strains that were part of the smear culture in this study. It was reported that the reduction of L. monocytogenes (WSLC 1364) was mostly $1 \mathrm{log} /$ $\mathrm{cm}^{2}$ in the presence of $D$. hansenii and $4 \mathrm{log} / \mathrm{cm}^{2}$ for $G$. candidum. Carnio et al. (1999) analyzed the bacterial ripening flora of German smeared cheeses with respect to their anti-listerial potential and found that Corynebacterium strains such as $C$. casei, which was also used in our study, have anti-listerial properties. However, their observations also indicated that selective pressure within the flora of the cheese surface might have resulted in the development of resistance mechanisms by micro-evolutionary adaptions of $L$. monocytogenes.

Our results indicate that a possibly existing antilisterial potential of $D$. hansenii, G. candidum, or $C$. case $i$ was not perceptible, or at a very low level. As the L. innocua strains were isolated from the surface of red smeared soft cheese, it cannot be excluded, however, that they had already developed resistance mechanisms as observed by Carnio et al. (1999). The relatively high salt content $(5 \% \mathrm{NaCl})$ of the smear culture also did not decrease the listerial load in the cheese rind. This is somewhat disappointing as hurdles such as competitive flora and salt should be effective against Listeria on the rind irrespective of whether the contamination originates from the cheese milk or from recontamination via the environment.

\section{CONCLUSIONS}

The produced raw milk Greyerzer cheeses showed typical microbiota in the cheese core and on the surface. Apart from the desirable starter and nonstarter lactic acid bacteria, smear bacteria (coryneforms and staphylococci), and yeasts, a typical contamination with enterobacteria and enterococci was also detected. The cheese surface also contained about $10^{6}$ to $10^{8} \mathrm{cfu} / \mathrm{g}$ of the 2 inoculated Listeria innocua strains throughout the entire ripening period despite the high concentration of smear bacteria. Obviously, the moist smear surface permitted an almost constant Listeria level, whereas in the core no Listeria was detectable at the end of ripening. The study shows that the smear culture developed no considerable anti-listerial potential. Considering that $L$. innocua is possibly even less resilient than L. monocytogenes against environmental stressors such as water activity, lactic acid bacteria, and dissolved $\mathrm{NaCl}$, a postprocess contamination by L. monocytogenes might be even more likely, posing a major hygienic risk when the rind is removed or such smeared cheese loaves are portioned with a cutting device.

\section{ACKNOWLEDGMENTS}

The authors thank Norbert Johannsen for the manufacture of the cheeses and Angelika Thoss for the chemical and physical analysis of products (Department of Safety and Quality of Milk and Fish Products), Svenja Feuerhahn (same department) and Kirsten Gonda (Department of Microbiology and Biotechnology) for microbiological analysis of inoculated strains and additional flora, respectively. We also thank Walter Bisig (Forschungsanstalt Agroscope Liebefeld-Posieux ALP, Bern, Switzerland) for recommendations of the manufacturing conditions.

\section{REFERENCES}

Bachmann, H. P., and U. Spahr. 1995. The fate of potentially pathogenic bacteria in Swiss hard and semihard cheeses made from raw milk. J. Dairy Sci. 78:476-483.

Bockelmann, W., K. P. Willems, H. Neve, and K. H. Heller. 2005. Cultures for the ripening of smear cheeses. Int. Dairy J. 15:719-732.

Boyer, R. R., S. S. Sumner, B. Meadows, R. C. Williams, J. D. Eifert, and W. Birbari. 2009. Survival of Listeria monocytogenes, Listeria innocua, and lactic acid bacteria in chill brines. J. Food Sci. 74:M219-M223.

Carnio, M., I. Eppert, and S. Scherer. 1999. Analysis of the bacterial surface ripening flora of German and French smeared cheeses with respect to their anti-listerial potential. Int. J. Food Microbiol. 47:89-97.

Chatelard-Chauvin, C., F. Pelissier, S. Hulin, and M. C. Montel. 2015. Behaviour of Listeria monocytogenes in raw milk Cantal type cheeses during cheese making, ripening and storage in different packaging conditions. Food Contr. 64:53-65.

Commission of the European Communities. 2005. Commission Regulation (EC) No 2073/2005 on microbiological criteria for foodstuffs. Dec. 22, 2005. Off. J. Eur. Union L 338:1-26.

Commission of the European Communities. 2007. Commission Regulation (EC) No 1441/2007 amending Regulation (EC) No 2073/2005 on microbiological criteria for foodstuffs. Dec. 5, 2007. Off. J. Eur. Union L 322:12-29.

Ercolini, D., V. Fusco, G. Blaiotta, F. Sarghini, and S. Coppola. 2005. Response of Escherichia coli O157:H7, Listeria monocytogenes, Salmonella typhimurium, and Staphylococcus aureus to the thermal stress occurring in model manufactures of Grana Padano cheese. J. Dairy Sci. 88:3818-3825.

Giannou, E., A. Kakouri, B. B. Matijasic, I. Rogelj, and J. Samelis. 2009. Fate of Listeria monocytogenes on fully ripened Greek Graviera cheese stored at 4,12 , or $25^{\circ} \mathrm{C}$ in air or vacuum packages: In 
situ PCR detection of a cocktail of bacteriocins potentially contributing to pathogen inhibition. J. Food Prot. 72:531-538.

Goerges, S., M. Koslowsky, S. Velagic, N. Borst, W. Bockelmann, K. J. Heller, and S. Scherer. 2011. Anti-listerial potential of food-borne yeasts in red smear cheese. Int. Dairy J. 21:83-89.

ISO. 2005. DIN EN ISO 11290-1 Microbiology of food and animal feeding stuffs - Horizontal method for the detection and enumeration of Listeria monocytogenes - Part 1: Detection method. DIN EN ISO 11290-1:2005-01. International Organization for Standardization, Geneva, Switzerland.

Kaufmann, U. 1989. Verhalten von Listeria monocytogenes während der Hartkäsefabrikation. Landwirtschaft Schweiz. 2:573-577.

Kheadr, E. E., J. F. Vachon, P. Paquin, and I. Fliss. 2002. Effect of dynamic high pressure on microbiological, rheological and microstructural quality of Cheddar cheese. Int. Dairy J. 12:435-446.

Kovincic, I., I. F. Vujicic, M. Svabic-Vlahovic, M. Vulic, M. Gagic, and I. V. Wesley. 1991. Survival of Listeria monocytogenes during the manufacture and ripening of Trappist cheese. J. Food Prot. 54:418-420.

Northolt, M. D., H. J. Beckers, U. Vecht, L. Toepoel, P. S. S. Soentoro, and H. J. Wisselink. 1988. Listeria monocytogenes: Heat resistance and behavior during storage of milk and whey and making Of Dutch types of cheese. Neth. Milk Dairy J. 42:207-219.

Pinto, M. S., A. F. de Carvalho, A. C. dos Santos, J. C. J. de Paula, D. Sobral, and F. A. R. Magalhães. 2009. Survival of Listeria innocua in Minas traditional Serro cheese during ripening. Food Contr. 20:1167-1170.
Rudolf, M., and S. Scherer. 2001. High incidence of Listeria monocytogenes in European red smear cheese. Int. J. Food Microbiol. 63:91-98.

Russell, N. J., R. I. Evans, P. F. TerSteeg, J. Hellemons, A. Verheul, and T. Abee. 1995. Membranes as a target for stress adaptation. Int. J. Food Microbiol. 28:255-261.

Ryser, E. T., and E. H. Marth. 1987. Behavior of Listeria monocytogenes during the manufacture and ripening of Cheddar cheese. J. Food Prot. 50:7-13.

Schvartzman,, M. S., A. Maffre, F. Tenenhaus-Aziza, M. Sanaa, E. Butler, and K. N. Jordan. 2011. Modelling the fate of Listeria monocytogenes during manufacture and ripening of smeared cheese made with pasteurised milk. Int. J. Food Microbiol. 145:S31-S38.

Terplan, G., R. Schoen, W. Springmeyer, I. Degle, and H. Becker 1996. Occurrence, behaviour and significance of Listeria in milk and dairy products. Arch. Lebensmittelhyg. 37:131-137.

Valdés-Stauber, N., H. Götz, and M. Busse. 1991. Antagonistic effects of coryneform bacteria from red smear cheese against Listeria species. Int. J. Food Microbiol. 13:119-130.

VDLUFA (Association of German Agricultural Analytic Research Institutes). 2003. Methodenbuch Band VI: Chemische, physikalische und mikrobiologische Untersuchungsverfahren für Milch, Milchprodukte und Molkereihilfsstoffe. VDLUFA, Darmstadt, Germany.

Yousef, A. E., and E. H. Marth. 1990. Fate of Listeria monocytogenes during the manufacture and ripening of Parmesan cheese. J. Dairy Sci. 73:3351-3356. 